\title{
Correction to: Mitigation of the liquefaction potential of soil by Ca-carbonate precipitation induced by indigenous urease-producing Staphylococcus sp. IR-103
}

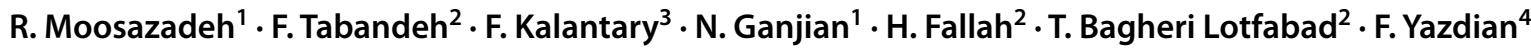

Published online: 11 August 2018

(C) Islamic Azad University (IAU) 2018

\section{Correction to: International Journal of Environmental Science and Technology \\ https://doi.org/10.1007/s13762-018-1788-6}

The original version of this article unfortunately contained a mistake.

The second affiliation of the first author R. Moosazadeh was incorrect. The corrected affiliation is given in this correction.

The original article can be found online at https://doi.org/10.1007/ s13762-018-1788-6.

F. Tabandeh

taban_f@nigeb.ac.ir

1 Department of Geotechnical Engineering, Science and Research Branch, Islamic Azad University, Tehran, Iran

2 Department of Industrial and Environmental Biotechnology, National Institute of Genetic Engineering and Biotechnology (NIGEB), 14965161, Tehran 1497716316, Iran

3 Department of Geotechnical Engineering, Khaje Nasir Toosi University of Technology, Tehran, Iran

4 Department of Biomedical Engineering, Faculty of Interdisciplinary New Sciences and Technologies, Tehran University, Tehran 14395-1561, Iran 